\section{A polymorphic microsatellite repeat sequence on chromosome 21 (D21S80)}

\section{M.J.Owen ${ }^{*}$, A.M.Goate ${ }^{1}$ and J.A.Hardy ${ }^{1}$}

Departments of Psychological Medicine and Medical Genetics, University of Wales College of Medicine, Heath Park, Cardiff CF4 4XN and ${ }^{1}$ Department of Biochemistry and Molecular Genetics, St Mary's Hospital Medical School, London W2 1PG, UK

Source/Description: The probe cM21 (D21S80) (1) was employed to isolate a cosmid from a library constructed from a mouse/human chromosome 21 as the only human chromosomal material (2). A Sau3A digest of the cosmid was inserted into M13 vector. Plaques that hybridised to a poly-GT oligodeoxynucleotide were sequenced. The sequence (CA) $)_{11}$ GCACTCTTGCACTC $(\mathrm{CA})_{4}$ was identified in one of the subclones. Oligodeoxynucleotide primers were constructed in order to allow this region to be amplified by PCR.

Primer 1: $\left(5^{\prime}-3^{\prime}\right)$ CTTGCCTAATTGACTATGAG

Primer 2: $\left(5^{\prime}-3^{\prime}\right)$ TTTATGTACGTGTATGTTTG

Polymorphism: Four alleles have been detected. Allele A1 $136 \mathrm{bp}$, allele $\mathrm{A} 2-134 \mathrm{bp}$, allele $\mathrm{A} 3-132 \mathrm{bp}$ and allele A4 -128 bp.

Frequency: Estimated from 50 unrelated Caucasians.

Heterozigosity $=0.31$

A1: 0.02

A2: 0.02

A3: 0.82

A4: 0.14

Chromosomal Localisation: The cosmid from which this polymorphic sequence was isolated contains the locus D21S13. This has been mapped using somatic cell hybrids and pulsedfield gel electrophoresis to 21q11 (3).

Mendelian Inheritance: Co-dominant segregation has been observed in 24 meioses.

Other Comments: ${ }^{35} \mathrm{~S}$-labelled PCR products were mixed with formamide loading buffer, heat denatured and run on a $6 \%$ polyacrylamide sequencing gel.

References: 1) Neve et al. (1986) Gene 49, 361-369. 2) Raziuddin et al. Proc. Natl. Acad. Sci. USA 81, 5504-5508. 3) Owen et al. (1990) Am. J. Hum. Genet. 46, 316-322.

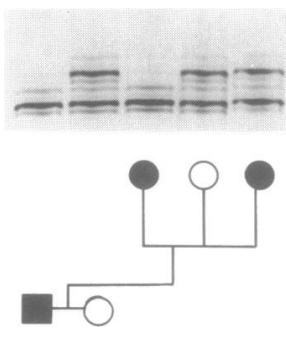

* To whom correspondence should be addressed

\section{Bgll RFLP for the human erb-A $\beta$ locus on chromosome 3p22 - 3p24.1 (THRB)}

Ch.Kanaka, A.Eblé and P.E.Mullis*

University of Bern, Department of Paediatrics, Inselspital, $\mathrm{CH}-3010$ Bern, Switzerland

Source/Description: PheA4 is a $1.5 \mathrm{~kb}$ EcoRI fragment from the human placenta c-erbA cDNA described by Weinberger, et al. (1), inserted in the EcoRI site of pGEM3.

Polymorphism: $B g l$ identifies a two allele polymorphism with bands either at $13.8 \mathrm{~kb}(\mathrm{~A} 1)$ or $9.7 \mathrm{~kb} / 3.68 \mathrm{~kb}$ (A2) and invariant bands at $15.1 \mathrm{~kb}, 8.8 \mathrm{~kb}, 4.6 \mathrm{~kb}, 4.05 \mathrm{~kb}, 2.08 \mathrm{~kb}$.

Frequency: Studied in 49 unrelated healthy Caucasians.

$\mathrm{A} 1=0.57$

$\mathrm{A} 2=0.43$

Not Polymorphic For: MspI, BglII, EcoRI, AluI, HindIII, HincII, NcoI, PstI and SmaI.

Chromosomal Localisation: Human erb- $\mathrm{A} \beta$ has been mapped to chromosome 3p22-3p24.1 (2).

Mendelian Inheritance: Co-dominant inheritance of alleles A1 and A2 was observed in 31 individuals from 6 families.

Probe Availability: Probe available on request from Ronald M. Evans, Salk Institute, San Diego (USA).

Acknowledgements: This work was supported by grants from Swiss National Science Foundation $(32-28580.90)$. We thank R.M. Evans for supplying the PheA4 probe.

References: 1) Weinberger et al. (1986) Nature 324, 641-646. 2) Drabkin et al. (1988) Proc. Natl. Acad. Sci. USA 85 , 9258-9262.

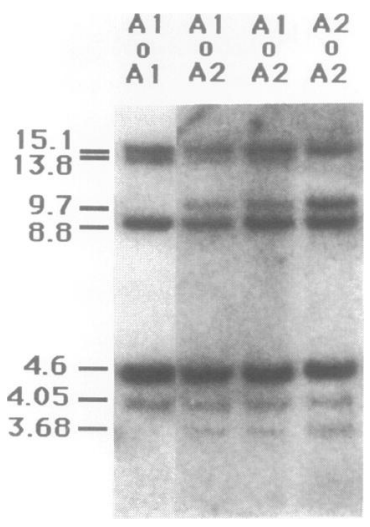

* To whom correspondence should be addressed 